\title{
The Role of Civility and Anonymity on Perceptions of Online Comments
}

\author{
Joseph Graf, Joseph Erba \& Ren-Whei Harn
}

To cite this article: Joseph Graf, Joseph Erba \& Ren-Whei Harn (2017) The Role of Civility and Anonymity on Perceptions of Online Comments, Mass Communication and Society, 20:4, 526-549, DOI: $10.1080 / 15205436.2016 .1274763$

To link to this article: https://doi.org/10.1080/15205436.2016.1274763

$$
\text { 曲 Published online: } 21 \text { Feb } 2017 .
$$

Submit your article to this journal

Цlll Article views: 557

View Crossmark data $\nearrow$

Citing articles: 2 View citing articles 


\title{
The Role of Civility and Anonymity on Perceptions of Online Comments
}

\author{
Joseph Graf \\ School of Communication \\ American University \\ Joseph Erba and Ren-Whei Harn \\ William Allen White School of Journalism and Mass Communications \\ The University of Kansas
}

An experiment was conducted $(N=170)$ to determine the role of civility and anonymity in online comments received for a news story. Dependent variables were (a) interest in the discussion, (b) favorability toward the comments, (c) favorability toward the commenter, and (d) trust in the information. Participants exposed to uncivil comments viewed the commenter less favorably and reported less trust in the information in the comment. Anonymity had no effect on the dependent variables, in contrast to expectations derived from social presence theory. Findings revealed that politeness of comments affected participants' overall perceptions of the content of the online discussion.

Joseph Graf (M.A., The Ohio State University, 1994) is an assistant professor in the School of Communication at American University. His research interests include online comments, new technology, and political communication.

Joseph Erba (Ph.D., University of North Carolina at Chapel Hill, 2013) is an assistant professor in the William Allen White School of Journalism and Mass Communications at the University of Kansas. His research interests include intersection of identities, such as race/ethnicity, class, and gender, on message development and interpretation.

Ren-Whei Harn (M.A., University of Kansas, 2013) is a doctoral student in the William Allen White School of Journalism and Mass Communications at the University of Kansas. Her research interests include the nexus of interaction design, social media and social support.

Correspondence should be addressed to Joseph Graf, 4400 Massachusetts Avenue NW, School of Communication, American University, Washington, DC 20016-8017. E-mail: graf@american.edu

Color versions of one or more of the figures in the article can be found online at www.tandfonline. com/hmcs. 
Incivility and negativity on the Internet are part of our academic and public discourse. Some of the earliest scholarly work about online discussion boards found a great deal of uncivil and angry comments (e.g., Benson, 1996; Davis, 1999; Wilhelm, 2000), and there is a body of research on "flaming," which is hostile and aggressive behavior online (summarized in O'Sullivan \& Flanagin, 2003). Internet incivility is also part of public conversation. Cyberbullying on social media and in online games is endemic and regularly appears in the news media (e.g., Wingfield, 2014). Significant numbers of people report they have witnessed name calling, threats, and harassment online, especially targeted at women (Pew Research Center, 2014).

Comments posted online in response to news stories represent another arena of incivility (Coe, Kenski, \& Rains, 2014; Diakopoulos \& Naaman, 2011; Paskin, 2010; Santana, 2011), even though there are venues of civil and polite discussions online (e.g., Hurrell, 2005; Papacharissi, 2004). Many news media sites allow online comments, and those comments attract readers and hence are valuable to the sites. Journalists generally feel that readers and viewers should be able to post comments, although they dislike the criticism that comes with it (Diakopoulos \& Naaman, 2011; Nielsen, 2012; Santana, 2011). In some cases, media outlets have closed comments sections because of arguments and personal attacks, or limited who can post (Farhi, 2014). National Journal, for example, ended comments on most stories because of name calling and racist and sexist language (Grieve, 2014). Popular Science magazine banned all online comments out of fears that uncivil and skeptical comments could influence the credibility of its science journalism (LaBarre, 2013).

There is evidence that uncivil comments may be influential in some situations, such as surrounding scientific claims or in politically polarized forums. For example, some readers of uncivil comments that were skeptical of a scientific innovation (nanotechnology) perceived greater risk (Anderson, Brossard, Scheufele, Xenos, \& Ladwig, 2013), and readers of uncivil politically polarized comments perceived the underlying issue to be more politically polarized (Hwang, Kim, \& Huh, 2014). Uncivil comments have often been linked with the degree of anonymity of the commenter (Halpern \& Gibbs, 2013; Moore, Nakano, Enomoto, \& Suda, 2012; Rowe, 2015; Santana, 2014). Greater anonymity is associated with more uncivil behavior.

This study explores the relationship between incivility and anonymity on online news readers' overall perceptions of comments and commenters. This is done in the context of news stories that are less controversial and political, as these variables may influence responses. This study thus aims to (a) test the effects of civil and uncivil comments in less controversial, nonpolitical news stories and (b) investigate how audiences respond to anonymous comments (both civil and uncivil). 


\section{LITERATURE REVIEW}

\section{Incivility}

The Internet did not introduce incivility. American public life has often been uncivil, and observers believe it grew more so in the 1990s. Incivility in public debate and public institutions and negative political advertising increased (summarized in Brooks \& Geer, 2007) and has caused great concern among scholars, nonprofit foundations, and public officials (Mutz \& Reeves, 2005). Members of Congress traveled to a bipartisan retreat in 1997 to "seek a greater degree of civility" (Jamieson \& Falk, 1998, p. 2). Richardson (2001) pointed to a "veritable torrent" of scholarly research on negative political campaigns in the 1990s (p. 791). The conventional wisdom among scholars was that negativity and incivility undermined democratic life, principally by discouraging public participation, but research generally did not support this. Negative campaign discourse or advertising does not appear to consistently discourage voting, although it may lessen political efficacy and trust in government (Lau, Sigelman, \& Rovner, 2007).

Negativity and incivility are different but related concepts. Whereas negativity addresses advertising, civility generally refers to the overall tone of campaigns, or to discourse in legislative bodies such as Congress (Jamieson \& Falk, 1998). More recently, civility has been considered an aspect of campaign advertising distinct from negativity (Brooks \& Geer, 2007; Mutz \& Reeves, 2005). Campaign advertising can have both tone (positive or negative) and civility (civil or uncivil). It matters not only if a candidate is pointed or negative but also how they express themselves, whether they are civil or not. For our purposes it is important that negativity and incivility are separated conceptually and empirically (Brooks \& Geer, 2007; Fridkin \& Kenney, 2011).

A lot of research on online comments focuses on incivility, but it has no dominant overarching theoretical framework. As in research on negative campaign advertising, there is a general belief that uncivil behavior is detrimental and in opposition to the goals of discursive deliberation. One framework scholars have embraced is the concept of flaming, which arose from popular culture as a term for angry, hostile, and profane online communication, primarily on discussion boards, but the concept can be applied to e-mail, online video, and other online communication (O'Sullivan \& Flanagin, 2003). The concept is almost exclusively linked to online communication, not face-to-face communication, and the study of flaming often is concerned with the presence or absence of social cues that influence our behavior online (O'Sullivan $\&$ Flanagin, 2003). The lack of social cues such as facial expressions and the lack of personal accountability encourage flaming. Psychologists call this "the online disinhibition effect" (Suler, 2004, p. 321), and anonymity appears to increase disinhibition (Moore et al., 2012; Rowe, 2015; Suler, 2004). However, although such research has explored the level of civility used in online comments, there is a dearth 
of studies investigating how readers of uncivil and anonymous comments perceive them. Prior to discussing the role that civility plays in online comments, it is important to differentiate civility from politeness, as the conceptualization of these terms directly affects their operationalization.

\section{Civility and Politeness}

In research on online discourse there often is no clear distinction between civility (or incivility) and politeness (or impoliteness), about which there is a rich literature (Watts, 2005). There is a fair amount of confusion between the terms, and they are defined differently by different groups. For example, Reader (2012) found a deep disconnect about the definition of civility between newspaper journalists and their online readers. Some scholars use politeness and civility interchangeably (Anderson et al., 2013; Ng \& Detenber, 2005). Papacharissi (2004) separated the terms conceptually and empirically and argued that politeness references etiquette, formality, and an adherence to norms that guide smooth conversation, whereas civility fosters democratic or deliberative goals. She found that online discussion comments can be either, both, or neither. Although the terms civility and politeness are often conflated in common usage, one can be civil without being polite by, for example, welcoming robust and spirited political debate that shows civility but not necessarily politeness.

In recent communication research there is a generally accepted operationalization of what constitutes uncivil language. Online comments and discussion are often considered uncivil if they include name calling, personal attacks, hyperbole, or rudeness. Gervais (2013) defined uncivil discourse as "claims that are deliberately disrespectful and insulting, or those presented in a hyperbolic nature" and operationalized it along the same lines, measuring degrees of name calling and exaggeration (p. 8). Anderson and her colleagues (2013) operationalized impolite or uncivil comments as name calling, as did Borah (2013). Incivility is likewise operationalized as "disrespectful statements or attacks" toward someone else (Hwang et al., 2014), or name calling, threats, and personal attacks (Ng \& Detenber, 2005; Papacharissi, 2004).

We agree with Papacharissi (2004) that politeness is a more narrow concept. The terms polite and impolite emphasize language, and not the larger set of social norms and obligations inferred by civility. One can be polite, with proper manners and language, and yet be uncivil. Civility is communication guided by democratic principles of fairness, equal access, and recognition of the value of reasoning (reciprocity), not just manners and etiquette. Incivility, such as a personal attack, threatens these principles by discouraging participation. The term civil society makes sense in the context of deliberative democratic discourse - the term "polite society" suggests Emily Post. We defer to the broad usage of the terms civility and incivility in research about online discourse and adopt them here. 


\section{Incivility and Polarization}

Research on online discourse couches the study of incivility within the context of deliberative discussion and has focused on its effects on political polarization. This approach is grounded in an appreciation for deliberation as essential for a democratic society and a consideration of the potential for the Internet to enrich deliberation (Freelon, 2010). Like civility, deliberation has attracted a great deal of scholarship and interest from government and nonprofit foundations (Delli Carpini, Cook, \& Jacobs, 2004). Deliberation in this context is generally thoughtful discussion that is civil, or devoid of aspersions and name calling. Uncivil discussion is theorized to be damaging to deliberation because it dissuades people from participation and can be politically polarizing. ${ }^{1}$ Uncivil comments can prompt feelings of aversion and decrease satisfaction with the online exchange, which is necessary for successful deliberation.

Research suggests civility (or uncivility) prompts similar behavior and may affect how readers perceive the news story. Civil comments may be modeled by discussants, who then act civil (Han \& Brazeal, 2015). Likewise, exposure to like-minded incivility prompted readers to be more likely to use incivility (Gervais, 2015). Uncivil online text discussion after a video news story prompted subjects to perceive greater political polarization surrounding the issue (health care reform), but they reported no change in their political views (Hwang et al., 2014). Similarly, an experiment found that "partisan" comments, which were generally uncivil, ${ }^{2}$ prompted readers to view the accompanying news story as biased and negative (Houston, Hansen, \& Nisbett, 2011). These partisan comments also had a third-person effect — readers thought stories with partisan comments would have a greater effect on others than themselves. Exposure to uncivil discussion eroded subjects' expectation that public deliberation works, or that deliberation could successfully address the policy problem at hand (Hwang et al., 2014).

The context surrounding online comments may also be important to how readers perceive the credibility of the news. When a news story was embedded within a politically partisan and uncivil blog, readers lent greater credibility to the story (Thorson, Vraga, \& Ekdale, 2010). Similarly, subjects who read an uncivil blog commentary first would then lend greater credibility to a news story, but they reported less political trust and political efficacy (Borah, 2013).

Online incivility has also been studied within the context of understanding health and science and the perception of risk. Exposure to uncivil discussion alone did not affect the risk a reader associated with an innovation, in this case, nanotechnology (Anderson et al., 2013). However, there was a polarizing interaction effect with

\footnotetext{
${ }^{1}$ Some scholars have argued otherwise and claim that civility is not necessary for democratic governance and deliberation (Estlund, 2001; Sanders, 1997).

${ }^{2}$ Although not labeled uncivil, the comments used in the experimental protocol fit the conceptual definition. They used name calling and aspersions ("What about McCain saying we will be in Iraq for 100 years?? What a loser he doesn't want our troops out of Iraq"; Houston et al., 2011, pp. 82-83).
} 
incivility and prior predispositions. People exposed to uncivil comments who strongly supported nanotechnology perceived less risk, whereas those who opposed nanotechnology saw more risk. In the arena of health-related public service announcement, online comments that are seen as civil influenced the response to an online public service announcements about vaccination (Kareklas, Muehling, \& Weber, 2015), which is a topic both scientific and political.

In sum, there is evidence that uncivil comments after news stories turn people off the online exchange and encourage readers to be uncivil. Politicized comments or a politicized "context" - an article posted on a political blog - may prompt readers to view the article as politicized. On the other hand, incivility may lend credibility to a news story, perhaps because the story appears as a contrast to the comments. All these studies manipulated the content of online comments but did not manipulate the presence or absence of identifiable commenters. That is, the focus of these studies was on the language used in comments and did not allow them to also explore the potential effects of anonymity on participants' reactions to the comments. Furthermore, these studies explored the effects of online comments using stimuli involving political and controversial topics, such as health care reform and the Iraq War. The present study investigates the effects of comments' level of civility and anonymity in less controversial news stories, as previous studies have suggested a relationship between incivility and anonymity.

\section{Anonymity}

Anonymity is another important consideration in online behavior and is often considered a factor encouraging incivility (Borah, 2013; Scott, Rains, \& Haseki, 2011). Journalists generally dislike anonymity in reader comments, although some journalists report that comments are useful to generate story ideas or get feedback (Reader, 2012; Santana, 2011). Readers recognize the vitriolic nature of online comments but favor allowing anonymous comments and view them as empowering and liberating (Reader, 2012; Rosenberry, 2011). Readers also embrace anonymity as a guard against the loss of privacy and the "vilification of dissent" (Reader, 2012, p. 505). One commenter argued that "anonymity allows people to speak truth to powerful institutions" (p. 503). In fact, Rosenberry (2011) noted the historic role anonymous writings played in American political discourse in the 1700s. John Trenchard and Thomas Gordon (1755) anonymously published Cato's Letters in London, which inspired the anonymously written Federalist Papers of James Madison, Alexander Hamilton, and John Jay (1788/1961) and the American Revolution. Anonymity is also important in voting and other kinds of political activity and may encourage marginalized or minority groups to participate (Reader, Stempel, \& Daniel, 2004).

The concept of anonymity is rarely explicitly defined in studies about computermediated communication, and it is operationalized myriad ways (Scott et al., 2011). 
Anonymity can be broken down into technical anonymity and social anonymity (Christopherson, 2007). Technical anonymity is when there is no identifying information. Social anonymity is the perception that one is anonymous to others. Some studies operationalize anonymity with pseudonyms, with nicknames, or by comparing the absence of photos with photos.

Research across all kinds of online forums suggests that anonymity generally seems to encourage self-disclosure and participation (Christopherson, 2007; Scott et al., 2011). This is in line with the "online disinhibition effect," which should encourage this sort of self-disclosure and promote helping behavior, or what psychologists call "benign disinhibition." Anonymity also encourages "toxic disinhibition," which may lead to "rude language, harsh criticisms, anger, hatred, even threats" (Suler, 2004, p. 321). Online anonymity may also encourage group polarization, or the tendency of like-minded individuals to become more extreme after interacting online (summarized in Christopherson, 2007). Research on online comments supports this, suggesting that anonymity encourages more uncivil comments. Anonymous commenters were more likely to use uncivil language in online comments about immigration posted to three newspaper websites ${ }^{3}$ (Santana, 2014). Political comments on the Washington Post website were more uncivil than on the Post's Facebook page, which offers less anonymity (Rowe, 2015). Aggressive and uncivil language in online discussion groups was more likely from anonymous commenters (Moore et al., 2012). Overall, findings reveal that anonymous online commenters are more likely to use uncivil language, although identifying commenters does not preclude incivility.

The effects of anonymous comments, however, haven't been explored as thoroughly. Indeed, would anonymous uncivil comments have the same effect as nonanonymous uncivil comments? How does the presence or absence of anonymity affect audiences' perceptions of comments' content, both civil and uncivil? This study uses a social presence theory framework to shed light on these questions by exploring the relationship between comments' level of civility and anonymity, and online news readers' overall perceptions of comments and commenters in the context of less controversial political news stories.

\section{Social Presence Theory}

Social presence theory addresses how interfaces and design affect social presence, loosely defined as the "sense of being with another" (Biocca, Harms, \& Burgoon, 2003 , p. 456). Scholars in the field of human-computer interaction use social presence theory to consider how differences in interfaces affect the sense of social presence. Increasing social presence is often a design goal of interfaces and games - which has

\footnotetext{
${ }^{3}$ The Los Angeles Times, the Arizona Republic, and the Houston Chronicle.
} 
fostered most of the social presence literature - and the presumed effect of greater social presence is a greater awareness of and responsiveness to social cues. Lee (2004) defined social presence as "a psychological state in which virtual (para-authentic or artificial) social actors are experienced as actual social actors in either sensory or nonsensory ways" (p. 45). With social presence, we experience actors who are not physically there as real and present. Although generally seen as applying to virtual environments, in the case of online comments this definition suggests that people who are not physically present can seem to be present, depending on the degree of presence. The level of presence has been found to vary between face-to-face and online communication, in this case, synchronous text-based computer communication (Cortese \& Seo, 2012). With greater social presence we are more likely to regard other discussants more subjectively and react to them with more civility. As social presence declines, we tend to view messages as less friendly or less personal (Rice \& Love, 1987).

\section{HYPOTHESES AND RESEARCH QUESTIONS}

This research examines the effects of incivility and anonymity within the context of news stories that are less dramatic and polarizing than health care reform or partisan politics. The topic of a news story has been found to be related to the number of comments it generates and their incivility. For example, political figures were likely to attract an inordinate number of uncivil comments (Coe et al., 2014).

Discursive deliberation (online or offline) must encourage participation. Participants must feel engaged and welcome in a discussion for deliberation to take place (Dryzek, 2000; Gutmann \& Thompson, 1996). Prior work in a partisan political context has found that uncivil comments discourage deliberation (prompt feelings of aversion), whereas civil comments did not (Gervais, 2015). Our first set of hypotheses address how people perceive the comments and commenter, but unlike most other research (i.e., Gervais, 2015; Han \& Brazeal, 2015) we use less controversial and partisan stories. We are further looking at perceptions of the comments and commenters, rather than subjects' behavior. We propose that civil comments will generate more interest and will be seen more favorably, and that favorability will extend to the commenter. H1a, H1b, and H1c address this interest and favorability.

H1a: Participants exposed to an online comment that was civil, rather than uncivil, will report more interest in the discussion.

H1b: Participants exposed to an online comment that was civil, rather than uncivil, will view the comments more favorably.

H1c: Participants exposed to an online comment that was civil, rather than uncivil, will view the commenter more favorably. 
Online comments may affect how readers view the credibility of a news story, although research does not offer clear guidance. Uncivil comments after a political news story prompted readers to view the issue as more polarized (Hwang et al., 2014) and view the news story as more biased (Houston et al., 2011). This perception of bias in the story may hurt its credibility; the concepts are closely related. However, when a political news story was displayed within the context of partisan politics, the story was seen as more credible. Uncivil blog posts prompted readers to view the accompanying story as more credible (Thorson et al., 2010), and an uncivil blog commentary read first prompted readers to evaluate a news story as more credible (Borah, 2013). In H2 we continue to emphasize the less political nature of our protocol materials, and we address the credibility of the comment, not the story.

H2: Participants exposed to an online comment that was civil, rather than uncivil, will report more trust in the information in the comment.

A theorized effect of disinhibition that we observe is more uncivil comments when someone is allowed to do so anonymously (Rowe, 2015; Santana, 2014). Research on anonymity more generally suggests that anonymity encourages uncivil comments. However, it is unclear whether anonymous commentary is perceived any differently than comments that are named. Social presence theory suggests that when we see a photograph of someone, we have a greater sense of their presence, that they are a real human being (Biocca et al., 2003). With more social presence we may regard someone more civilly, and we may view their messages more positively. Similarly, no published research has explored the relationship between anonymous comments and trust in the information presented in comments. Therefore, we propose the following research questions to address these points and further our understanding of the effects of anonymity in online news comments.

RQ1: How does anonymity affect participants' perceptions of civil and uncivil comments and of the commenters?

RQ2: How does anonymity affect participants' perceptions of trust in the information presented?

\section{METHODS}

Participants were recruited via Amazon's Mechanical Turk, an online platform that provides access to a large pool of participants (Buhrmester, Kwang, \& Gosling, 2011). All participants received a $\$ 5$ credit to their Amazon account for their participation in this study. Participants $(N=170)$ took part in a 3 (commenters' photograph: White 
male individual, White female individual, anonymous) $\times 2$ (civility of comment: civil language; uncivil language) between-subjects experiment. A fictive online newspaper, Metro Local, was created for this experiment. All participants were randomly assigned to one of the six treatment conditions, in which they each read three news stories. The three news stories were identical across conditions, and each story included one reader's comment, which represented the experimental manipulation. After exposure to each news story, participants completed a questionnaire measuring the four main dependent variables: interest in the online discussion, perception of the comment, perception of the commenter, and trust in the information in the comment. Participants then answered questions about their overall perception of the website, their habits reading news online and commenting on stories, and general demographic variables. The study protocol and its materials were approved by American University's Institutional Review Board in March 2014.

\section{Participants}

A total of 182 U.S. participants from Amazon's Mechanical Turk platform completed the online experiment. Data from participants who did not answer all dependent variable items $(n=12)$ were deleted prior to analysis. Data from 170 participants were retained. Participants' age ranged from 18 to 76 years old $(M=34.20, S D=11.35)$. There were almost as many women $(51.2 \%, n=87)$ as men $(48.8 \%, n=83)$. Approximately two thirds of participants identified as "White or Caucasian" $(77.1 \%, n=131)$. About two fifths of participants had completed some college $(38.8 \%, n=66)$, and about one third had a college degree $(30.6 \%, n=52)$.

\section{Experimental Treatment Conditions}

A fictive online newspaper, Metro Local, was created for this experiment. The layout of the web page for Metro Local was identical for all treatment conditions, with the name of the newspaper predominantly displayed at the top of the page. Each page contained one story followed by a comment, which represented the stimulus material. Participants were exposed to a comment that used either civil or uncivil language, accompanied by the photograph of a White man; White woman; or, for the "anonymous" condition, a silhouette icon of a unisex headshot found in the online comment section of various online newspapers. (Two example stimuli are included in the appendix. Others are available by request from the first author.)

Each condition included three stories (presented in a random order) with a similar type of "treatment" comment from a different commenter. Therefore, three photographs of White men and three photographs of White women, all headshots, were needed to create the stimuli. Similarly, three gender-neutral names were used as 
commenters' names for the nonanonymous conditions. ${ }^{4}$ We operationalized civil and uncivil treatment levels with the inclusion or exclusion of name calling, aspersions, using synonyms for lying directed at someone, vulgarities, and pejorative words for speech, similar to other research (Anderson et al., 2013; Borah, 2013; Hwang et al., 2014; Ng \& Detenber, 2005). This allowed us to alter comments with just a few words; otherwise the stimuli were constant.

\section{Pretests}

Three pretests were conducted to develop the stimuli: one for the photographs of White men and women, one for the comments, and one for the news stories. Our goal was to control for the attractiveness of the commenter by choosing photographs that did not appear too attractive or unattractive in pretests and that could clearly be identified as Caucasian. Pretests for the comments were to ensure that "civil" and "uncivil" comments were perceived as such, and pretests for the news stories were to ensure that the stories were not perceived as overtly and clearly controversial or politically biased. We discuss this further in the study's limitations.

To determine which headshots to use in the stimuli, a pretest study was conducted with a sample of headshots of White men and women. Each picture was in color with a light brown background. Sixty-two undergraduate students were exposed to 25 headshots of White men and 25 headshots of White women in their early 20s. The order in which headshots appeared was randomized. Participants evaluated the headshots using a 7-point semantic differential scale composed of five items developed by Ohanian (1990) to measure celebrity endorsers' attractiveness: 1 (unattractive) to 7 (attractive); 1 (not classy) to 7 (classy); 1 (beautiful) to 7 (ugly); 1 (plain) to 7 (elegant); 1 (sexy) to 7 (not sexy). Participants were also asked to identify to which racial/ethnic group each person pictured in the headshots belonged (Asian, African American, Caucasian, Hispanic, Native American). All headshots were correctly identified as Caucasian. An attractiveness composite score was created for each of these headshots, and the means of the three male and female headshots closest to $3.50(3.32-3.69)$ were selected as stimuli images.

The participants who completed the pretest for the photographs were also asked to complete the pretest for the comments and news stories. Thirty-two participants took the second pretest and read 12 news stories with two comments per story. Participants rated the level of civility of each comment using a 7-point semantic differential scale composed of four item: 1 (polite) to 7 (impolite); 1 (courteous) to 7 (not courteous); 1 (respectful) to 7 (disrespectful); 1 (civil) to 7 (uncivil). We selected comments where the difference for each of the five items was significant at $p<.001$ ( $t$ tests). Participants also rated how controversial each story appeared:

\footnotetext{
${ }^{4}$ The names were Sam Reed, Chris Greene, and Jordan Watkins.
} 
1 (not controversial at all) to 7 (very controversial). The three stories selected were scored between 3.34 and 4.23 on the controversy scale. Thus, we believe our pretest ensured that the comments were clearly civil or uncivil, and our stories were not considered to be about controversial topics. Story 1 dealt with reducing sentences of low-level drug criminals, Story 2 dealt with the potential name change of the Washington Redskins football team, and Story 3 dealt with the aftermath of a hurricane on the northeast U.S. coast.

\section{Dependent Measures}

Interest in the Online Discussion. This variable was measured with a 7point scale, from 1 (strongly disagree) to 7 (strongly agree), composed of three items adopted from Ng and Detenber (2005). Items were "I would like to contribute a comment to this discussion," "I am interested in reading more of this discussion," and "I would like to become a member of this discussion group." Although our stimulus is only one comment, our concept of "interest" imagines a more general interest in an ongoing discussion.

Perception of the Comment. This variable was measured with a 7-point scale, from 1 (strongly disagree) to 7 (strongly agree), composed of five items from Zhao, Strasser, Cappella, Lerman, and Fishbein's (2011) argument strength scale, which evaluates arguments, such as the ones presented in comments, from multiple perspectives. Sample items included "The comment is believable," "The comment is convincing," and "The comment would help others think about this issue."

Perception of the Commenter. This variable was measured with a 7-point scale, from 1 (strongly disagree) to 7 (strongly agree), composed of five items similar to the one $\mathrm{Ng}$ and Detenber (2005) used to measure civility and trust. Sample items included "The person who made the comment seems respectful," "The person who made the comment seems reliable," and "The person who made the comment seems trustworthy."

Trust in the Information Presented. This variable was measured with a 7point scale, from 1 (strongly disagree) to 7 (strongly agree), composed of two items adopted from Zhao et al. (2011) to measure perceived trust in an argument. Items were "I trust the person making the comment" and "I trust the information presented in the comment."

\section{Demographic and Additional Measures}

Participants were asked to identify their gender, race, age, education level, and place of residence. Participants also answered questions pertaining to their perceptions of 
the Metro Local website, their media diet, the amount of time spent reading news online, and how often they engage in online news comments.

\section{Data Analysis}

Data were analyzed using SPSS. Twelve composite scores were created from the four dependent variables for each of the three news stories. Participants' responses to each news story were analyzed separately. Cronbach's alpha for three indices (interest in the online discussion, perception of the comment, and perception of the commenter) ranged from .85 (Story 3: interest in discussion) to .96 (Story 2: perception of commenter). Reliability for a two-item index is best determined using the Spearman-Brown coefficient (Eisinga, Grotenhuis, \& Pelzer, 2013). The coefficients for the two-item index "trust in the information presented" were significant at $p<.001$ level for all three stories (Story 1: $\rho=.91$; Story 2: $\rho=.93$; Story 3: $\rho=.90$ ).

\section{RESULTS}

We first tested for any effect of the gender of the commenter in the photographs and found none. To answer the research questions and test the hypotheses, a series of two-way 3 (commenter's photograph) $\times 2$ (civility of comment) analyses of variance were conducted to test the effect of the conditions on the dependent variables. Mean scores for the four dependent variables for the three stories are shown in Table 1.

H1a: Participants exposed to an online comment that was civil, rather than uncivil, will report more interest in the discussion. This hypothesis was not supported. No significant difference was found between participants who read a civil comment and participants who read an uncivil one regarding their interest in the online discussion for all news stories.

Hlb: Participants exposed to an online comment that was civil, rather than uncivil, will view the comments more favorably. The hypothesis was not supported. No significant difference was found between participants who read a civil comment and participants who read an uncivil one regarding how participants perceived the comments for all news stories.

Hlc: Participants exposed to an online comment that was civil, rather than uncivil, will view the commenter more favorably. This hypothesis was supported (see Table 2). Participants who read a civil comment perceived the commenter significantly more favorably than participants who read an uncivil comment, $F(1$, $155)=107.25, p<.001 ; F(1,159)=36.00, p<.001 ; F(1,158)=18.60, p<.001$, for Stories 1, 2 and 3, respectively.

H2: Participants exposed to an online comment that was civil, rather than uncivil, will report more trust in the information in the comment. This hypothesis was mostly supported as the analysis revealed significant results for Stories 1 and 2, 
TABLE 1

Means and Standard Deviations for All Dependent Variables and Experimental Conditions

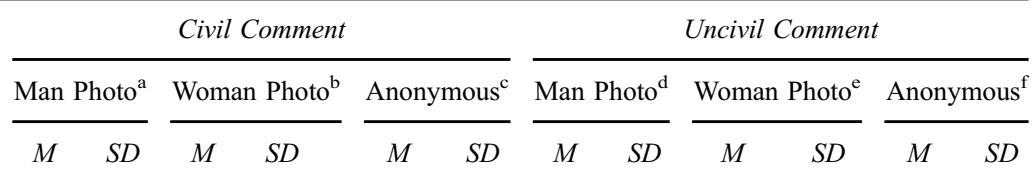

\begin{tabular}{|c|c|c|c|c|c|c|c|c|c|c|c|c|}
\hline \multicolumn{13}{|c|}{ Interest in online discussion } \\
\hline Story 1 & 3.96 & .34 & 4.07 & .30 & 4.16 & .31 & 4.56 & .33 & 4.21 & .32 & 3.80 & .32 \\
\hline Story 2 & 3.99 & .34 & 3.47 & .32 & 4.03 & .32 & 4.21 & .33 & 3.51 & .32 & 3.80 & .33 \\
\hline Story 3 & 4.01 & .32 & 3.38 & .28 & 3.41 & .29 & 3.93 & .31 & 3.69 & .30 & 3.56 & .30 \\
\hline \multicolumn{13}{|c|}{ Perception of comment } \\
\hline Story 1 & 3.20 & .32 & 2.96 & .27 & 3.62 & .28 & 3.10 & .30 & 2.52 & .29 & 2.77 & .30 \\
\hline Story 2 & 4.24 & .33 & 4.46 & .31 & 4.52 & .31 & 4.14 & .32 & 3.92 & .31 & 4.13 & .32 \\
\hline Story 3 & 5.41 & .25 & 5.50 & .22 & 5.68 & .22 & 5.35 & .24 & 5.16 & .23 & 5.17 & .23 \\
\hline \multicolumn{13}{|c|}{ Perception of commenter } \\
\hline Story 1 & 4.35 & .27 & 4.14 & .23 & 4.23 & .24 & 2.49 & .26 & 1.82 & .25 & 2.07 & .25 \\
\hline Story 2 & 4.23 & .30 & 4.43 & .28 & 4.32 & .28 & 3.21 & .29 & 2.76 & .28 & 2.86 & .29 \\
\hline Story 3 & 5.34 & .27 & 5.21 & .24 & 5.56 & .25 & 4.50 & .27 & 4.42 & .25 & 4.46 & .26 \\
\hline \multicolumn{13}{|c|}{ Trust in the information } \\
\hline Story 1 & 3.20 & .31 & 3.29 & .26 & 3.71 & .27 & 2.70 & .29 & 1.96 & .28 & 2.44 & .29 \\
\hline Story 2 & 3.98 & .35 & 4.03 & .33 & 4.29 & .33 & 3.60 & .35 & 3.24 & .33 & 3.35 & .34 \\
\hline Story 3 & 5.19 & .29 & 5.21 & .26 & 5.40 & .27 & 4.96 & .29 & 4.68 & .27 & 4.85 & .28 \\
\hline
\end{tabular}

${ }^{\mathrm{a}} n=25 .{ }^{\mathrm{b}} n=32 .{ }^{\mathrm{c}} n=29 .{ }^{\mathrm{d}} n=26 .{ }^{\mathrm{e}} n=30 .{ }^{\mathrm{f}} n=28$.

TABLE 2

A $3 \times 2$ Analysis of Variance for Participants' Perceptions of Commenters of the Three News Stories

\begin{tabular}{llrrrrr}
\hline & & $S S$ & $\mathrm{df}$ & $M S$ & $\mathrm{~F}$ & $\mathrm{p}$ \\
\hline Story 1 & $\mathrm{P}$ & 5.00 & 2 & 2.50 & 1.50 & .225 \\
& $\mathrm{C}$ & 178.35 & 1 & 178.35 & 107.25 & .000 \\
& $\mathrm{P} \times \mathrm{C}$ & 1.41 & 2 & .70 & .42 & .655 \\
& Error & 257.75 & 155 & 1.66 & & \\
Story 2 & $\mathrm{P}$ & .56 & 2 & .28 & .13 & .881 \\
& $\mathrm{C}$ & 79.23 & 1 & 79.23 & 36.00 & .000 \\
& $\mathrm{P} \times \mathrm{C}$ & 2.96 & 2 & 1.48 & .67 & .512 \\
& Error & 349.91 & 159 & 2.20 & & \\
Story 3 & $\mathrm{P}$ & 1.10 & 2 & .55 & .30 & .738 \\
& $\mathrm{C}$ & 33.50 & 1 & 33.50 & 18.60 & .000 \\
& $\mathrm{P} \times \mathrm{C}$ & .79 & 2 & .40 & .22 & .802 \\
& Error & 284.53 & 158 & 1.80 & & \\
\hline
\end{tabular}

Note. $\mathrm{SS}=$ sum of squares; $\mathrm{MS}=$ mean square; $\mathrm{P}=$ photograph; $\mathrm{C}=$ comment. 
TABLE 3

A $3 \times 2$ Analysis of Variance for Participants' Trust in the Information Presented in the Comments of the Three News Stories

\begin{tabular}{llrrrrr}
\hline & & \multicolumn{1}{c}{$S S$} & $\mathrm{df}$ & $M S$ & $\mathrm{~F}$ & $\mathrm{p}$ \\
\hline Story 1 & $\mathrm{P}$ & 6.00 & 2 & 3.00 & 1.40 & .249 \\
& $\mathrm{C}$ & 42.23 & 1 & 42.23 & 19.74 & .000 \\
& $\mathrm{P} \times \mathrm{C}$ & 5.42 & 2 & 2.71 & 1.27 & .285 \\
& Error & 3331.64 & 155 & 2.14 & & \\
Story 2 & $\mathrm{P}$ & 1.09 & 2 & .55 & .18 & .839 \\
& $\mathrm{C}$ & 20.49 & 1 & 20.49 & 6.59 & .011 \\
& $\mathrm{P} \times \mathrm{C}$ & 2.20 & 2 & 1.10 & .35 & .703 \\
& Error & 494.69 & 159 & 3.11 & & \\
Story 3 & $\mathrm{P}$ & .99 & 2 & .49 & .24 & .784 \\
& $\mathrm{C}$ & 7.68 & 1 & 7.68 & 3.77 & .054 \\
& $\mathrm{P} \times \mathrm{C}$ & .83 & 2 & .41 & .20 & .816 \\
& Error & 321.46 & 158 & 2.03 & & \\
\hline
\end{tabular}

Note. $\mathrm{SS}=$ sum of squares; $\mathrm{MS}=$ mean square; $\mathrm{P}=$ photograph; $\mathrm{C}=$ comment.

and marginal results for Story 3 (see Table 3). Participants who read a civil comment reported more trust in the information presented than participants who read an uncivil comment, $F(1,155)=19.74, p<.001 ; F(1,159)=6.59, p<.05 ; F(1$, $158)=3.78, p=.054$, for Stories 1,2 and 3, respectively.

RQ1: How does anonymity affect participants' perceptions of civil and uncivil comments and of the commenters? No relationship was found among these variables, as participants reported similar perceptions of anonymous commenters and comments (civil and uncivil) than of photographed commenters and comments.

RQ2: How does anonymity affect participants' perceptions of trust in the information presented? Anonymity does not affect trust in the information, as participants perceived similar levels of trust in the information presented in comments, regardless of who the comments were from.

\section{DISCUSSION}

Research on the effects of online comments is limited. Much of the research about the effects of uncivil comments examines its effects on behavior (i.e., Han \& Brazeal, 2015) and examines comments in the context of overtly partisan or political issues (Hwang et al., 2014; Ng \& Detenber, 2005). Similarly, the literature on the effects of anonymity also focuses on behavior (Moore et al., 2012; Santana, 2014). One exception is research that examines the effects of context on credibility or perceptions of bias, but always within a political context (Borah, 2013; Houston et al., 2011). 
Our contribution is an examination of the effects of incivility and anonymity on the perceptions of comments and commenters, conducted with stories that are not overtly political or controversial. In our experiment, we used three news stories that were pretested as less controversial, which may explain why our results differ from previous studies. Although the three news stories were overall less controversial, they also dealt with three different topics, thus reinforcing external validity of our study. Our results imply that online news readers' perceptions of a news story may be more influenced by the story itself than by another reader's comment. Our results indicate that the civility of a comment does not influence online news readers' perceptions of that comment, but the civility of a comment does influence perceptions of the commenter and trust in the information. Our results suggest that perception of the content of a comment or interest in the discussion is more dependent on individual differences than civility alone. However, our study did not ask participants about their level of agreement with the comments they read, which may have helped us explore what makes a comment likeable or not.

The effect of civility in a comment was strong on how it was perceived across all three stories. Perception of the comment was conceptualized as being believable, convincing, making a good point, and helping others think about the topic. Our findings on trust were more equivocal - significant for Stories 1 and 2 but marginal for Story $3(p=.054)$. This could be explained by the higher levels of trust given to Story 3 . There may be less effect of incivility when the material is more trusted to begin with, whereas less trusted content leaves open the challenge to its credibility that uncivil comments may provide.

Our work challenges the finding that uncivil comments dissuade people from wanting to post comments online, or at least expressing an interest in the comments section. Gervais (2015) found that those exposed to uncivil political discussion expressed anger and dissatisfaction to what he termed "histrionic incivility," which was identical to "mild incivility" but with capitalized select exclamations (p. 174). In other words, uncivil comments in all caps - the online version of yelling-prompted anger and dissatisfaction. This suggests that the culprit is not incivility as it is currently conceived and operationalized among communication researchers. Our operationalization of incivility is much closer to Gervais's "mild-incivility" (p. 174). It may be the case that the real distinction is between incivility and histrionics, or what Sobieraj and Berry (2011) called outrage, or "incivility writ large" (p. 20). All outrage is uncivil, but not all incivility is outrageous. Outrage includes mockery, belittling, obscenity, character assassination, and emotional language, among other things. The operationalization of incivility that we use here is common (see, e.g., Anderson et al., 2013; Borah, 2013; Hwang et al., 2014; Ng \& Detenber, 2005), but it is not histrionic and perhaps not "uncivil enough" to deter readers from the discussion or influence their perceptions of the comments. That may require comments that 
escalate to outrage. As Sobieraj and Berry pointed out, outrage is common too, especially in the new media environment of political blogs, political talk radio, and cable news.

A civil comment prompted more favorable perceptions of commenters, thus suggesting that online news readers may associate the language used in comments to the character and likeability of commenters. This makes perfect sense: Those people who post civil comments are viewed more favorably than those who do not. Online readers make distinctions between the comment and the commenter. Readers find that uncivil comments reflect badly on the commenter but have no effect on whether the comment is believable or convincing. This suggests that researchers cannot lump together effects as either "positive" or "negative" and expect them to covary.

Our results support prior findings that civility influences trust; however, here we see this effect in a context outside politics or controversy. This is particularly interesting because our results suggest that online news readers are making a conceptual difference between how they perceive the content of a comment (not affected by civility) and how they perceive trust in the content of a comment (affected by civility). Although perceptions of comments may be based on individual differences, civility plays a role in perceptions of trust in the information presented in comments. Because online news readers trusted civil comments more than uncivil ones, online news media publications may be worrying too much about the potential impact of uncivil online comments on the larger public discourse or on the dissemination of information.

Although research suggests the influence of anonymity on a person's behavior (Christopherson, 2007; Scott et al., 2011), our results indicate that anonymity does not affect online news readers' perceptions of comments and commenters, regardless of the level of civility. The fact that commenters were identifiable by name and photograph did not prompt readers to perceive a comment more favorably. Even for uncivil comments, anonymous comments were not perceived less favorably. In addition, anonymity played no role on the trust that online news readers placed in the information contained in comments, whether the comments were civil or uncivil. Trust, as mentioned earlier, was directly related to comments' level of civility. Online news readers were more likely to trust information presented in a civil manner, even if they could not see who was presenting the information, as was the case for anonymous comments.

\section{CONCLUSION}

The purpose of this study was to explore the effects of a civil, uncivil, and anonymous online comment on audiences' interest in the online discussion, their perceptions of comments and commenters, and their perceived trust in the 
information presented. As comments have increasingly become part of reading news online, there has been an ongoing debate about how audiences should comment online, as well as the influence these comments may have on readers. Some sites have banned anonymous comments in the hopes of enhancing civility. As anonymous comments are often linked to uncivil language and as news organizations are making decisions about their comment sections, it is paramount to investigate the effects of these online comments.

As hypothesized, findings revealed that a civil comment elicited more favorable perceptions about the commenter than an uncivil comment. Similarly, audiences were more likely to trust the information presented in a civil comments than in an uncivil one, suggesting that civility may translate to trustworthiness. However, the level of civility of a comment had no effect on perceptions of the comment itself. Audiences interpreted the use of uncivil language more as a reflection of the commenter than of the content of the comment.

Overall, audiences responded in a similar manner to comments made anonymously or comments made from an identifiable commenter, whose name and photograph were displayed. Although no significant effects of anonymous comments were found, this may be one of the main contributions of this study, as it suggests that requiring commenters to identify themselves would not change online news readers' perceptions of the comments and would not affect their trust in the information in these comments. Online news publications may be giving too much importance to the role that comments play in audiences' overall experiences, as neither uncivil comments nor anonymous ones affected audiences' interest in participating in the online discussion for any of the three news stories in this study.

Previous studies have examined uncivil or anonymous comments mostly by using one news story about a controversial topic. To advance our understanding of the effects of online comments on audiences and to increase its validity, this study combined uncivil and anonymous comments and used three news stories about topics that were pretested as less controversial. Nonetheless, there were limitations to this approach. Many of these limitations are due to the contrived nature of laboratory experiments as a research method. Little research has been conducted in this area. Therefore, our research program begins at the beginning: a laboratory experiment, with only one comment as the independent variable (not a full discussion), on a fairly simple website. The presence of additional comments may have influenced our results as each additional comment and commenter is a potential confound. Experiments such as this may suffer from poor external validity if subjects are not influenced by the independent variables as they might be in a real-world context. Our website was not as "busy" as typical news media websites, with advertisements, teasers, and multiple comments. It lacks the interactive nature of many news websites. Participants were presented with only one comment and did not have the opportunity to write their own comment if they wished. We further used stories that 
pretest subjects did not find particularly controversial, although this could be subject to debate. What is not controversial to one subject may be highly so to another. Finally, we make a trade-off in our research design between what we see as the strengths of repeating our stimulus across three stories and the weaknesses of repeated identical measures of our dependent variables, which may include order effects. This issue is somewhat offset by the randomization of the stimuli stories.

One advantage to our work is multiple tests. Even if the "less controversial" news stories elicited different reactions we still obtained similar results across all dependent variables for all three news stories except for the relationship between level of civility of a comment and trust in the information presented, for which we found significant results for two stories and marginal results for the third story. Such nuanced findings would not have emerged from studies that only use one stimulus, as is the case in the majority of experimental design studies. Similarly, our use of three news stories to test our hypotheses and explore our research questions increases the strengths of all our other findings. In this research area, replication of results across different stimuli and conditions is needed.

Limitations of this experimental study provide potential future research opportunities in examining interactive elements we commonly see in online forum designs. Besides anonymity, future studies should explore how elements such as comment ratings or the number of commenters' followers influence perception and trust. Once a comment is shared, what cues can promote ongoing interaction and prevent conversational breakdowns? The design of the fictive online story can also be modified to test how display design affects attention and information processing. This work has also been focused on "noncontroversial" and "nonpartisan" material, as best we could determine. We believe this is the correct approach for early studies, but future studies might address controversial and political material, especially in the context of civility, because of the growing uncivility in political discourse and the wide reach of this discourse in our daily lives.

\section{FUNDING}

Support for this project was provided by a faculty research and projects grant to the first two authors by the dean of the School of Communication, American University.

\section{REFERENCES}

Anderson, A. A., Brossard, D., Scheufele, D. A., Xenos, M. A., \& Ladwig, P. (2013). The "Nasty Effect:" Online incivility and risk perceptions of emerging technologies. Journal of ComputerMediated Communication, 19, 373-387. 
Benson, T. W. (1996). Rhetoric, civility, and community: Political debate on computer bulletin boards. Communication Quarterly, 44, 359-378.

Biocca, F., Harms, C., \& Burgoon, J. K. (2003). Toward a more robust theory and measure of social presence: Review and suggested criteria. Presence: Teleoperators and Virtual Environments, 12, 456-480.

Borah, P. (2013). Interactions of news frames and incivility in the political blogosphere: Examining perceptual outcomes. Political Communication, 30, 456-473.

Brooks, D. J., \& Geer, J. G. (2007). Beyond negativity: The effects of incivility on the electorate. American Journal of Political Science, 51, 1-16.

Buhrmester, M., Kwang, T., \& Gosling, S. D. (2011). Amazon's mechanical turk: A new source of inexpensive, yet high-quality data? Perspectives on Psychological Science, 6, 3-5.

Christopherson, K. M. (2007). The positive and negative implications of anonymity in Internet social interactions: "On the Internet, nobody knows you're a dog". Computers in Human Behavior, 23, 3038-3056.

Coe, K., Kenski, K., \& Rains, S. A. (2014). Online and uncivil? Patterns and determinants of incivility in newspaper website comments. Journal of Communication, 64, 658-679.

Cortese, J., \& Seo, M. (2012). The role of social presence in opinion expression during FtF and CMC discussions. Communication Research Reports, 29, 44-53.

Davis, R. (1999). The web of politics: The Internet's impact on the American Political System. New York, NY: Oxford University Press.

Delli Carpini, M. X., Cook, F. L., \& Jacobs, L. R. (2004). Public deliberation, discursive participation, and citizen engagement: A review of the empirical literature. Annual Review of Political Science, 7, 315-344.

Diakopoulos, N., \& Naaman, M. (2011). Towards quality discourse in online news comments. Proceedings of the CSCW 2011 Conference on Computer Supported Cooperative Work (pp. 133-142). New York, NY: ACM.

Dryzek, J. S. (2000). Deliberative democracy and beyond: Liberals, critics and contestations. New York, NY: Oxford University Press.

Eisinga, R., Grotenhuis, M. T., \& Pelzer, B. (2013). The reliability of a two-item scale: Pearson, Cronbach, or Spearman-Brown? International Journal of Public Health, 58, 637-642.

Estlund, D. (2001). Deliberation down and dirty: Must political expression be civil? In T. R. Hensley (Ed.), The boundaries of freedom of expression \& order in American Democracy (pp. 46-67). Kent, OH: Kent State University Press.

Farhi, P. (2014, 8 May). News Web sites' new tack: Take a toll on trolls. The Washington Post, p. C01.

Freelon, D. G. (2010). Analyzing online political discussion using three models of democratic communication. New Media \& Society, 12, 1172-1190.

Fridkin, K. L., \& Kenney, P. J. (2011). Variability in citizens' reactions to different types of negative campaigns. American Journal of Political Science, 55, 307-325.

Gervais, B. T. (2013). Incivility in online political discourse and anti-deliberative attitudes: An experimental analysis. Paper presented at the annual meeting of the American Political Science Association, Chicago, IL, September 2013.

Gervais, B. T. (2015). Incivility online: Affective and behavioral reactions to uncivil political posts in a web-based experiment. Journal of Information Technology \& Politics, 12, 167-185.

Grieve, T. (2014). Why we're changing our comments policy. National Journal. Retrieved from http://www.nationaljournal.com/domesticpolicy/why-we-re-changing-our-comments-policy20140516

Gutmann, A., \& Thompson, D. (1996). Democracy and disagreement. Cambridge, MA: Belknap Press.

Halpern, D., \& Gibbs, J. (2013). Social media as a catalyst for online deliberation? Exploring the affordances of Facebook and YouTube for political expression. Computers in Human Behavior, 29, $1159-1168$. 
Han, S.-H., \& Brazeal, L. M. (2015). Playing nice: Modeling civility in online political discussions. Communication Research Reports, 32, 20-28.

Houston, J. B., Hansen, G. J., \& Nisbett, G. S. (2011). Influence of user comments on perceptions of media bias and third-person effect in online news. Electronic News, 5, 79-92.

Hurrell, A. C. (2005). Civility in online discussion: The case of the foreign policy dialogue. Canadian Journal of Communication, 30, 633-648.

Hwang, H., Kim, Y., \& Huh, C. U. (2014). Seeing is believing: Effects of uncivil online debate on political polarization and expectations of deliberation. Journal of Broadcasting \& Electronic Media, 58, 621-633.

Jamieson, K. H., \& Falk, E. (1998). Civility in the House of Representatives: An update. Retrieved from http://www.annenbergpublicpolicycenter.org/Downloads/Political_Communication/ 105thCongressCivil/REP20.PDF

Kareklas, I., Muehling, D. D., \& Weber, T. J. (2015). Reexamining health messages in the digital age: A fresh look at source credibility effects. Journal of Advertising, 44, 88-104.

LaBarre, S. (2013). Why we're shutting off our comments. Popular Science. Retrieved from http:// www.popsci.com/science/article/2013-09/why-were-shutting-our-comments

Lau, R. R., Sigelman, L., \& Rovner, I. B. (2007). The effects of negative political campaigns: A metaanalytic reassessment. The Journal of Politics, 69, 1176-1209.

Lee, K. M. (2004). Presence, explicated. Communication Theory, 14, 27-50.

Madison, J., Hamilton, A., \& Jay, J. (1961). The Federalist Papers. New York, NY: New American Library. (Original work published 1788)

Moore, M. J., Nakano, T., Enomoto, A., \& Suda, T. (2012). Anonymity and roles associated with aggressive posts in an online forum. Computers in Human Behavior, 28, 861-867.

Mutz, D. C., \& Reeves, B. (2005). The new videomalaise: Effects of televised incivility on political trust. The American Political Science Review, 99, 1-15.

Ng, E. W. J., \& Detenber, B. H. (2005). The impact of synchronicity and civility in online political discussions on perceptions and intentions to participate. Journal of Computer-Mediated Communication, 10.

Nielsen, C. (2012). Newspaper journalists support online comments. Newspaper Research Journal, $33,86-100$.

Ohanian, R. (1990). Construction and validation of a scale to measure celebrity endorsers' perceived expertise, trustworthiness, and attractiveness. Journal of Advertising, 19(3), 39-52.

O'Sullivan, P. B., \& Flanagin, A. J. (2003). Reconceptualizing 'flaming' and other problematic messages. New Media \& Society, 5, 69-94.

Papacharissi, Z. (2004). Democracy online: Civility, politeness, and the democratic potential of online political discussion groups. New Media \& Society, 6, 259-283.

Paskin, D. (2010). Say what? Journal of International Communication, 16, 67-83.

Pew Research Center. (2014, October 22). Online harassment. Retrieved from http://www.pewinter net.org/2014/10/22/online-harassment/

Reader, B. (2012). Free press vs. free speech? The rhetoric of "Civility" in regard to anonymous online comments. Journalism and Mass Communication Quarterly, 83, 495-513.

Reader, B., Stempel, G. H., III, \& Daniel, D. K. (2004). Age, wealth, education predict letters to editor. Newspaper Research Journal, 25(4), 55-66.

Rice, R. E., \& Love, G. (1987). Electronic emotion: Socioemotional content in a computer-mediated communication network. Communication Research, 14, 85-108.

Richardson, G. W., Jr. (2001). Looking for meaning in all the wrong places: Why negative advertising is a suspect category. Journal of Communication, 51, 775-800.

Rosenberry, J. (2011). Users support online anonymity despite increasing negativity. Newspaper Research Journal, 32(2), 6-19. 
Rowe, I. (2015). Civility 2.0: A comparative analysis of incivility in online political discussion. Information, Communication \& Society, 18, 121-138.

Sanders, L. M. (1997). Against deliberation. Political Theory, 25, 347-376.

Santana, A. D. (2011). Online readers' comments represent new opinion pipeline. Newspaper Research Journal, 32(3), 66-81.

Santana, A. D. (2014). Virtuous or vitriolic: The effect of anonymity on civility in online newspaper reader comment boards. Journalism Practice, 8, 18-33.

Scott, C. R., Rains, S. A., \& Haseki, M. (2011). Anonymous communication: Unmasking findings across fields. In C. T. Salmon (Ed.), Communication Yearbook 35 (pp. 299-340). New York, NY: Routledge.

Sobieraj, S., \& Berry, J. M. (2011). From incivility to outrage: Political discourse in blogs, talk radio, and cable news. Political Communication, 28, 19-41.

Suler, J. (2004). The online disinhibition effect. Cyberpsychology \& Behavior, 7, 321-326.

Thorson, K., Vraga, E., \& Ekdale, B. (2010). Credibility in context: How uncivil online commentary affects news credibility. Mass Communication and Society, 13, 289-313.

Trenchard, J., \& Gordon, T. (1755). Cato's letters: Or, Essays on liberty, civil and religious, and other important subjects, in four volumes. London, UK: Printed for J. Walthoe, T. and T. Longman, C. Hitch and L. Hawes, J. Hodges, A. Millar, J. and J. Rivington, and M. Cooper.

Watts, R. J. (2005). Linguistic politeness research: Quo vadis? In R. J. Watts, S. Ide, \& K. Ehlich (Eds.), Politeness in language: Studies in its history, theory and practice (2nd ed., pp. xi-xlvii). New York, NY: Mouton de Gruyter.

Wilhelm, A. G. (2000). Democracy in the digital age. New York, NY: Routledge.

Wingfield, N. (2014, 16 October). Feminist critics of video games facing threats. The New York Times, p. A1.

Zhao, X., Strasser, A., Cappella, J. N., Lerman, C., \& Fishbein, M. (2011). A measure of perceived argument strength: reliability and validity. Communication Methods and Measures, 5, 48-75. 


\section{APPENDIX}

\section{Examples of Experimental Stimuli}

Example 1: Drug sentencing story, civil treatment, White man's comment

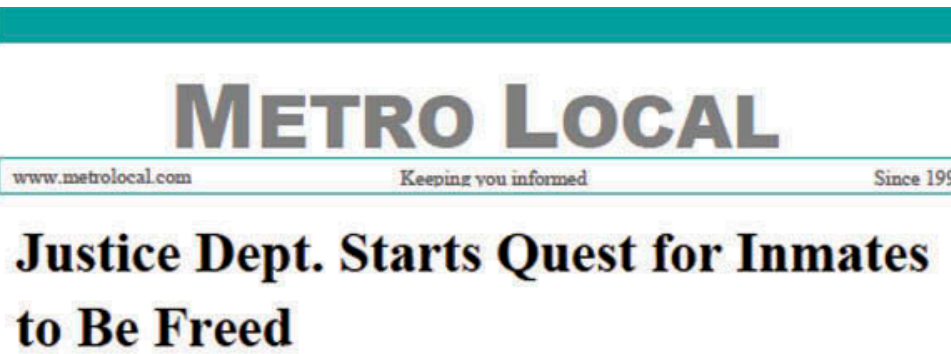

WASHINGTON - The Justice Department wants low-level drug criminals who were sentenced under tough laws from the days of the crack epidemic to ask the president for early release from prison.

In an unprecedented move, Deputy Attorney General James M. Cole asked defense lawyers on Thursday to help the government locate prisoners and encourage them to apply for clemency. The clemency drive is part of the Obama administration's effort to undo a disparity that flooded the nation's prison system and disproportionately affected black men.

Offenses involving crack, which was more commonly used in black communities, carried more severe penalties than crimes involving powder cocaine, which was usually favored by affluent white users. In some cases, crack crimes resulted in a 100-to-1 sentencing disparity.

Congress reduced that disparity in 2010. In December, President Obama commuted the sentences of eight federal inmates who received sentences under the old rules.

"There are more low-level, nonviolent drug offenders who remain in prison, and who would likely have received a substantially lower sentence if convicted of precisely the same offenses today," Mr. Cole said at a New York State Bar Association event. "This is not fair, and it harms our criminal justice system."

\section{COMMENTS:}

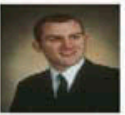

Sam Reed wrote:

I think that your argument might be wrong and that you might be looking at it from the wrong perspective. You should try putting yourself into the shoes of someone who has faced these kinds of sentences. 
Example 2: Drug sentencing story, uncivil treatment, White man's comment

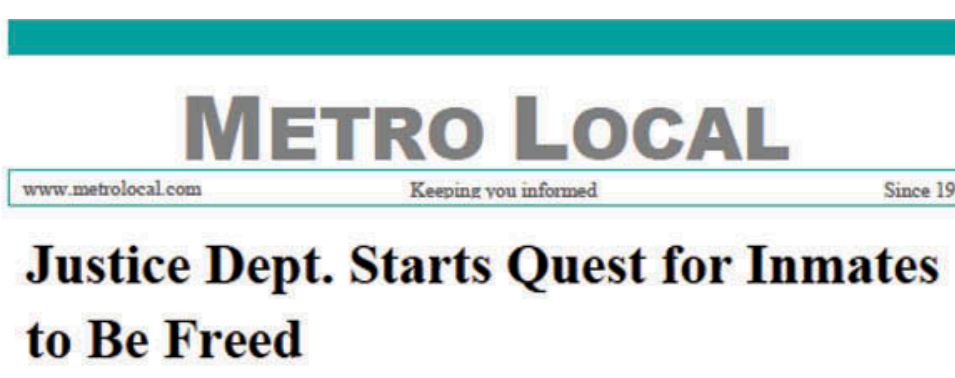

\begin{abstract}
WASHINGTON - The Justice Department wants low-level drug criminals who were sentenced under tough laws from the days of the crack epidemic to ask the president for early release from prison.
\end{abstract}

In an unprecedented move, Deputy Attorney General James M. Cole asked defense lawyers on Thursday to help the govemment locate prisoners and encourage them to apply for clemency. The clemency drive is part of the Obama administration's effort to undo a disparity that flooded the nation's prison system and disproportionately affected black men.

Offenses involving crack, which was more commonly used in black communities, carried more severe penalties than crimes involving powder cocaine, which was usually favored by affluent white users. In some cases, crack crimes resulted in a 100-to-1 sentencing disparity.

Congress reduced that disparity in 2010. In December, President Obama commuted the sentences of eight federal inmates who received sentences under the old rules.

"There are more low-level, nonviolent drug offenders who remain in prison, and who would likely have received a substantially lower sentence if convicted of precisely the same offenses today," Mr. Cole said at a New York State Bar Association event. "This is not fair, and it harms our criminal justice system."

\title{
COMMENTS:
}

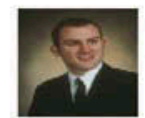

Sam Reed wrote:

Your argument is total crap. You are really thinking about this from the wrong perspective, doofus, if you can call it thinking. You need to put yourself into the shoes of someone who has faced these kinds of sentences. 